University of New Hampshire

University of New Hampshire Scholars' Repository

$10-2012$

\title{
Did the arctic ice recover? Demographics of true and false climate facts
}

Lawrence C. Hamilton

University of New Hampshire, lawrence.hamilton@unh.edu

Follow this and additional works at: https://scholars.unh.edu/soc_facpub

Part of the Sociology Commons

\section{Recommended Citation}

Hamilton, L.C. Did the arctic ice recover? Demographics of true and false climate facts. (2012) Weather, Climate, and Society, 4 (4), pp. 236-249.

This Article is brought to you for free and open access by the Sociology at University of New Hampshire Scholars' Repository. It has been accepted for inclusion in Sociology Scholarship by an authorized administrator of University of New Hampshire Scholars' Repository. For more information, please contact Scholarly.Communication@unh.edu. 


\title{
Did the Arctic Ice Recover? Demographics of True and False Climate Facts
}

\author{
LAWRENCE C. HAMILTON \\ Department of Sociology, University of New Hampshire, Durham, New Hampshire
}

(Manuscript received 1 February 2012, in final form 17 August 2012)

\begin{abstract}
Beliefs about climate change divide the U.S. public along party lines more distinctly than hot social issues. Research finds that better-educated or informed respondents are more likely to align with their parties on climate change. This information-elite polarization resembles a process of biased assimilation first described in psychological experiments. In nonexperimental settings, college graduates could be prone to biased assimilation if they more effectively acquire information that supports their beliefs. Recent national and statewide survey data show response patterns consistent with biased assimilation (and biased guessing) contributing to the correlation observed between climate beliefs and knowledge. The survey knowledge questions involve key, uncontroversial observations such as whether the area of late-summer Arctic sea ice has declined, increased, or declined and then recovered to what it was 30 years ago. Correct answers are predicted by education, and some wrong answers (e.g., more ice) have predictors that suggest lack of knowledge. Other wrong answers (e.g., ice recovered) are predicted by political and belief factors instead. Response patterns suggest causality in both directions: science information affecting climate beliefs, but also beliefs affecting the assimilation of science information.
\end{abstract}

\section{Introduction}

Since the idea that human emissions of carbon dioxide could alter the Earth's climate was first proposed by Swedish chemist Svante Arrhenius in 1896, it has developed from a scientific hypothesis into a broad area of research, cumulatively drawing on data from many different fields (Weart 2008). In recent decades, however, even as the scientific consensus strengthened, dissensus among the U.S. public deepened (Dunlap and McCright 2008). Beliefs about the reality of global warming, or more broadly anthropogenic climate change, became a new wedge issue dividing the U.S. public along party lines more distinctly than hot social issues. ${ }^{1}$ Many

\footnotetext{
${ }^{1}$ For example, unpublished analysis of the 2010 General Social Survey finds a Democrat-Republican gap of 20 points on human evolution (evolved), 20 points on abortion (abany), and 31 points on whether a temperature rise from climate change would be dangerous for the environment (tempgen1). More starkly worded questions asked on a July 2012 statewide poll in New Hampshire elicit a Democrat-Republican gap of 26 points on human evolution, 41 points on legal abortion, and 51 points on whether human activities are changing the climate.
}

Corresponding author address: Lawrence C. Hamilton, Department of Sociology, University of New Hampshire, Durham, NH 03824.

E-mail: Lawrence.Hamilton@unh.edu people base their beliefs about physical reality on what they think would be the socioeconomic or political implications if human-caused climate change were true.

One striking feature of public beliefs about climate change has been the pattern of information-elite polarization. Surveys find that college-educated respondents are more likely than others to line up with their parties on climate change. Similarly, respondents who express greater confidence in their own understanding of the issue, and even those who score better on science-literacy scales, show wider partisan and ideological divisions (Hamilton 2008, 2011a; Hamilton and Keim 2009; Hamilton et al. 2012; Kahan et al. 2011a,b; McCright 2011; McCright and Dunlap 2011). Belief and concern about anthropogenic climate change increase with education or science literacy among individuals who identify themselves as Democrats or liberals, but do not increase (and may even decrease) with education or literacy among Republicans and conservatives.

This pattern resembles the outcome of biased assimilation leading to attitude polarization, a process observed in experimental data by Lord et al. (1979; developed further by Munro and Ditto 1997; Munro et al. 2002; Corner et al. 2011). Biased assimilation refers to the selective acquisition or interpretation of new information in ways that reinforce preexisting beliefs. Experimental exposure to new information therefore 
can increase polarization. In the nonexperimental world of public beliefs about climate change, more educated individuals likely are more effective in acquiring new information themselves through news media, blogs, and other sources, and in framing new information they encounter. Often their efforts tend to strengthen existing beliefs instead of change them, leading to greater polarization. Similar ideas arise frequently in studies of climate change beliefs, with varied theoretical frameworks including mental models (Bostrom et al. 1994; Read et al. 1994; Leiserowitz et al. 2010; Reynolds et al. 2011), cultural cognition (Kahan et al. 2011a), motivated skepticism and confirmation bias (Taber and Lodge 2006), ideological filtering and information processing (Borick and Rabe 2010; Wood and Vedlitz 2007), elite cues (Brulle et al. 2012; Darmofal 2005; Krosnik et al. 2000), or reinforcing spirals (Zhao 2009).

Biased assimilation (along with other frameworks) implies that people's general beliefs about the reality or causes of climate change can influence their acceptance of specific information such as reports from scientists. For example, recent Arctic warming has been widely characterized by scientists as evidence of climate change, and specifically of the polar amplification predicted by climate models (Solomon et al. 2007; Richardson et al. 2009). Arctic ice loss, with its consequences for polar bears, resource development and territorial claims, has drawn media attention and rising public awareness (Hamilton et al. 2012). Countering scientific reports of unusual warming, however, have been other narratives mainly from nonexpert sources suggesting that Arctic warming is not well established, or just cyclical, or has already reversed. Such counternarratives have been widely publicized too, supplying people who do not believe climate is changing with information that reinforces their own beliefs. Thus, perceptions about Arctic trends could sometimes be a consequence of general beliefs, rather than simply being information that helps to shape those beliefs in the first place. Some other specific climate facts and arguments likely have this attribute as well. The following sections examine survey questions on climate beliefs and knowledge for signs of such effects.

\section{Survey questions about climate beliefs and knowledge}

Our data come from a series of random-sample telephone surveys conducted in 2011 and 2012. Since 2001, the Granite State Poll has surveyed random samples of about 500 New Hampshire residents four times each year. Interviewers ask a variety of background, political opinion, voting, and other topical questions. Starting in
2010, climate change questions were added to the mix. Several recurring questions now form a unique quarterly time series tracking public opinion about climate change (Hamilton 2011b). In June 2011, the Granite State Poll also began testing climate-related science questions. Table 1 gives the wording for six climate belief or knowledge questions, with New Hampshire poll results in the right-hand column.

Four of these questions also were carried on a U.S. national survey called the National Community and Environment in Rural America (NCERA) in August 2011. NCERA was designed by Carsey Institute researchers to provide national benchmarks comparable to their Community and Environment in Rural America (CERA) regional surveys (Hamilton and Keim 2009). The left-hand column in Table 1 gives response percentages for the climate questions on NCERA. Both NCERA and the Granite State Poll employ random sampling with probability-weighting methods and check results against Census profiles to ensure results that represent U.S. or New Hampshire populations.

Our belief and knowledge questions are stated in neutral, fact-oriented terms. None mention values or policy choices. The climate changing now/human option of Belief CC corresponds to the main point of public statements on climate change by major science organizations and national academies (e.g., American Association for the Advancement of Science 2007; National Research Council of the National Academies 2010). Knowledge questions each address central and welldiscussed observations upon which both contrarian and mainstream scientists agree. They do not address attribution, and as survey questions do not require agreement that anthropogenic climate change presents a serious problem.

Response percentages in Table 1 show substantial similarity between U.S. and New Hampshire results. Slightly more than half the respondents believe that climate change is happening now, caused mainly by human activities. Around $70 \%$ know that Arctic sea ice covers less area than it did 30 years ago. Just over $60 \%$ know that carbon dioxide concentration is rising, and $55 \%$ correctly identify the meaning of "greenhouse effect." Two more difficult questions about volcanoes and sea level, from the most recent New Hampshire survey, draw pluralities of "don't know" responses.

Figure 1 charts the demographic bases of climate belief on the NCERA national survey. Bars indicate the weighted percentage who believe that climate change is happening now, caused mainly by human activities. There are gender and age effects, with stronger impacts from education. Political party, however, dominates the demographic predictors of climate beliefs. 
TABLE 1. Survey questions about climate beliefs and facts, with weighted response percentages from the U.S. national NCERA survey (August 2011, $n=2006$ ) and New Hampshire statewide surveys (June 2011 to April 2012, $n=2139$ for Belief CC, 1,601 for Greenhouse, 516-538 for others). Response order was rotated on all surveys.

\section{US}

NH

Belief CC

Which of the following three statements do you personally believe?

Climate change is happening now, caused mainly by human activities.

Climate change is happening now, but caused mainly by natural forces.

Climate change is NOT happening now.

Don't know/no answer

$\begin{array}{rr}52 & 55 \\ 39 & 35 \\ 5 & 4 \\ 4 & 6\end{array}$

Arctic ice

Which of the following three statements do you think is more accurate?

Over the past few years, the ice on the Arctic Ocean in late summer...

Covers less area than it did 30 years ago.

Declined but then recovered to about the same area it had 30 years ago.

Covers more area than it did 30 years ago.

Don't know/no answer

$\begin{array}{rr}68 & 71 \\ 11 & 10 \\ 8 & 7 \\ 12 & 12\end{array}$

Keeling

Which of the following three statements do you think is more accurate?

Scientific measurements have confirmed that in recent decades, the concentration of $\mathrm{CO}_{2}$ or carbon dioxide in the Earth's atmosphere is ...

Increasing

Staying about the same

Decreasing

Don't know/no answer

63

16

11
55

4

6

Greenhouse

Which of the following three statements do you think is more accurate?

Scientists use the term 'greenhouse effect' to describe ...

The heat-trapping properties of certain gases, such as carbon dioxide or $\mathrm{CO}_{2}$.

A hole in the Earth's ozone layer, which allows more sunlight to get through.

The warming effect of pavement and cities.

Don't know/no answer

$\begin{array}{rr}55 & 53 \\ 24 & 25 \\ 7 & 7 \\ 13 & 14\end{array}$

Volcano

Which of the following two statements do you think is more accurate?

Over the past few decades,

Human activities have released much more $\mathrm{CO}_{2}$ than volcanoes.

Humans and volcanoes have release about the same amounts of $\mathrm{CO}_{2}$.

Volcanoes have released much more $\mathrm{CO}_{2}$ than humans.

Don't know/no answer

$\begin{array}{ll}- & 33 \\ - & 16 \\ - & 13 \\ - & 38\end{array}$

Sealevel

Which of the following possible changes would, if it happened, do the most to raise sea levels?

Melting of land ice in Greenland and the Antarctic.

Melting of glaciers in the Himalaya and Alaska.

Melting of sea ice on the Arctic Ocean.

Don't know/no answer

$\begin{array}{ll}- & 31 \\ - & 10 \\ - & 21 \\ - & 39\end{array}$

\section{Real and perceived Arctic ice}

The area of ice covering Arctic seas has declined visibly through the period of satellite observation. Reduction has been statistically significant in every month of the year, but most pronounced in late summer when the northern annual cycle reaches its minimum. Figure 2 tracks five different indexes of mean September ice cover [Fig. 2 graphs mean September ice area or extent from four sources: University of Bremen (Institute of Environmental Physics 2011); National Snow and Ice Data Center (NSIDC) (National Snow and Ice Data Center 2011); International Arctic Research Center (IARC)-Japan Aerospace Exploration Agency (JAXA) Information System (IJIS) (Japan Aerospace Exploration Agency 2011); University of Illinois (Polar Research Group 2011)]. 


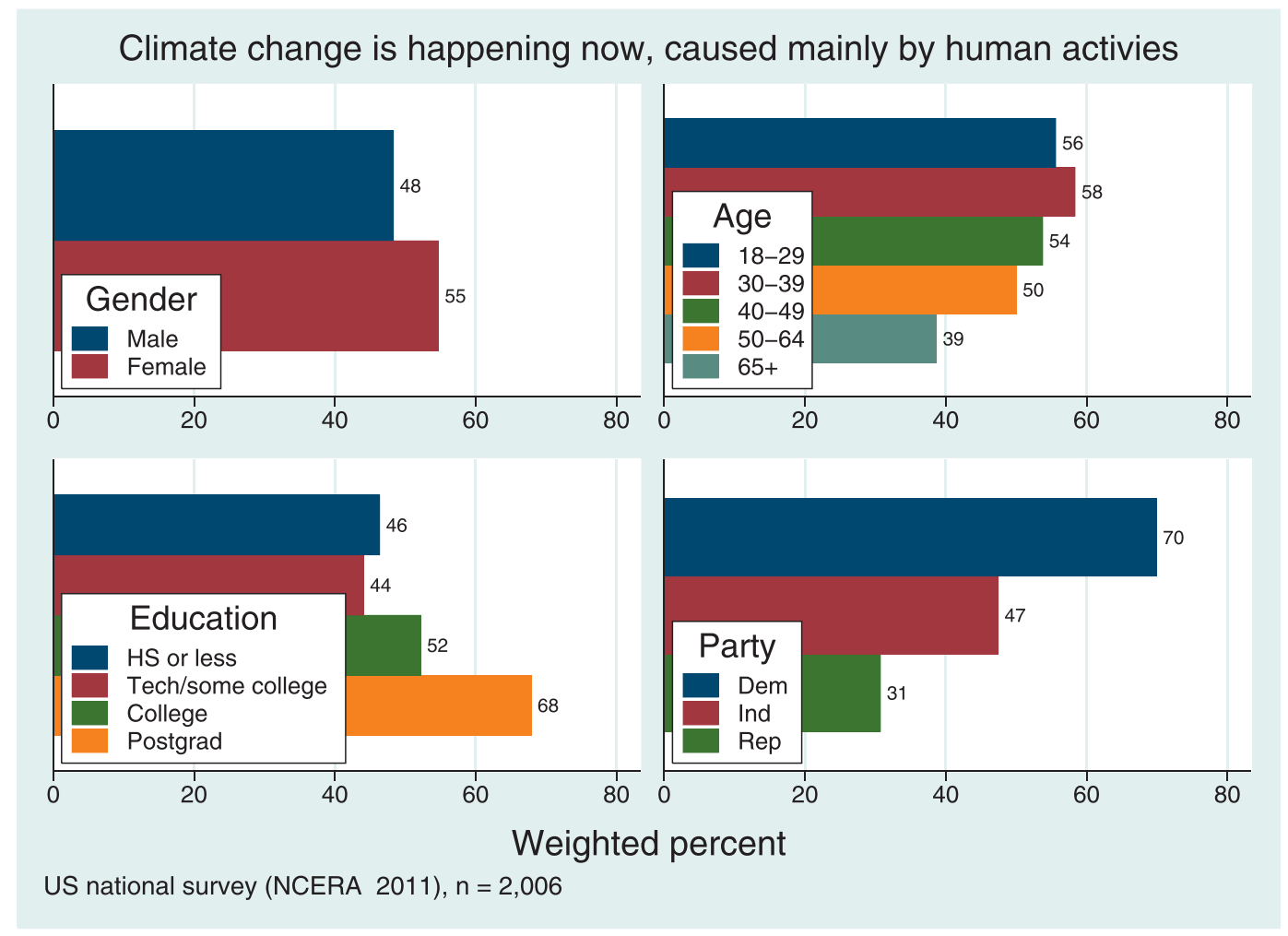

FIG. 1. Demographic bases of personal belief about climate change.

Satellite-based measures of ice cover have declined since the late 1970s. This decline took a dramatic step in 2007 , fluctuated slightly above this level over the next three years, then reached new low points in 2011. The Polar Research Group at the University of Illinois reported that area set a new one-day record, slightly below the previous record from 2007 (Polar Research Group 2011). The September 2011 record was $28 \%$ below any value prior to 2007 , and $38 \%$ below the lowest values before 1990 . Also in September 2011, scientists at the University of Bremen's Institute of Environmental Physics reported a record minimum for Arctic sea ice extent (the area with at least $15 \%$ ice), while the University of Washington's Polar Science Center calculated a record minimum for Arctic sea ice volume (Institute of Environmental Physics 2011; Polar Science Center 2011). Other teams measuring Arctic sea ice reported low if not record values.

Although daily satellite observations go back only to the 1970s, declassified Cold War submarine observations show that Arctic ice has been declining since the 1950s, so the remaining cover increasingly consists of thinner seasonal ice (Kwok and Rothrock 2009). Historical records indicate that the seasonal ice zone, an area of northern seas that is ice-covered in winter but not in late summer, has been expanding gradually since 1870 , and more rapidly in the past three decades (Kinnard et al. 2008). Proxy evidence suggests that the recent declines in Arctic sea ice extent and volume are unprecedented over the past 1450 years (Kinnard et al. 2011) if not more (Polyak et al. 2010), as is the intrusion of warmer Atlantic waters into the Arctic Ocean (Spielhagen et al. 2011). In the past few decades, shelves of glacial ice more than 3000 years old have broken apart owing to warming in the Canadian Arctic (England et al. 2008). Thus, a broad range of indicators at decadal to millennial time scales confirm the exceptional nature of ice reductions that have recently been observed in the Arctic.

Declining Arctic sea ice has been widely mentioned in news media accounts, especially around notable events such as the historical records set in 2007 (National Oceanic and Atmospheric Administration 2011), or a submarine planting a Russian flag on the seafloor at the North Pole that same year. Concern over suggestions that sea ice decline could threaten polar bear survival (e.g., Durner et al. 2009) have been popularized as well. Public misconceptions that sea ice can substantially affect sea level bring further attention to this topic (Leiserowitz et al. 2010). Numerous blogs post regular ice graphs, maps, and reports; organized betting occurs on the minimum extent or area. More systematic evidence for public awareness comes from the General Social Survey, which in 2006 and 2010 asked 


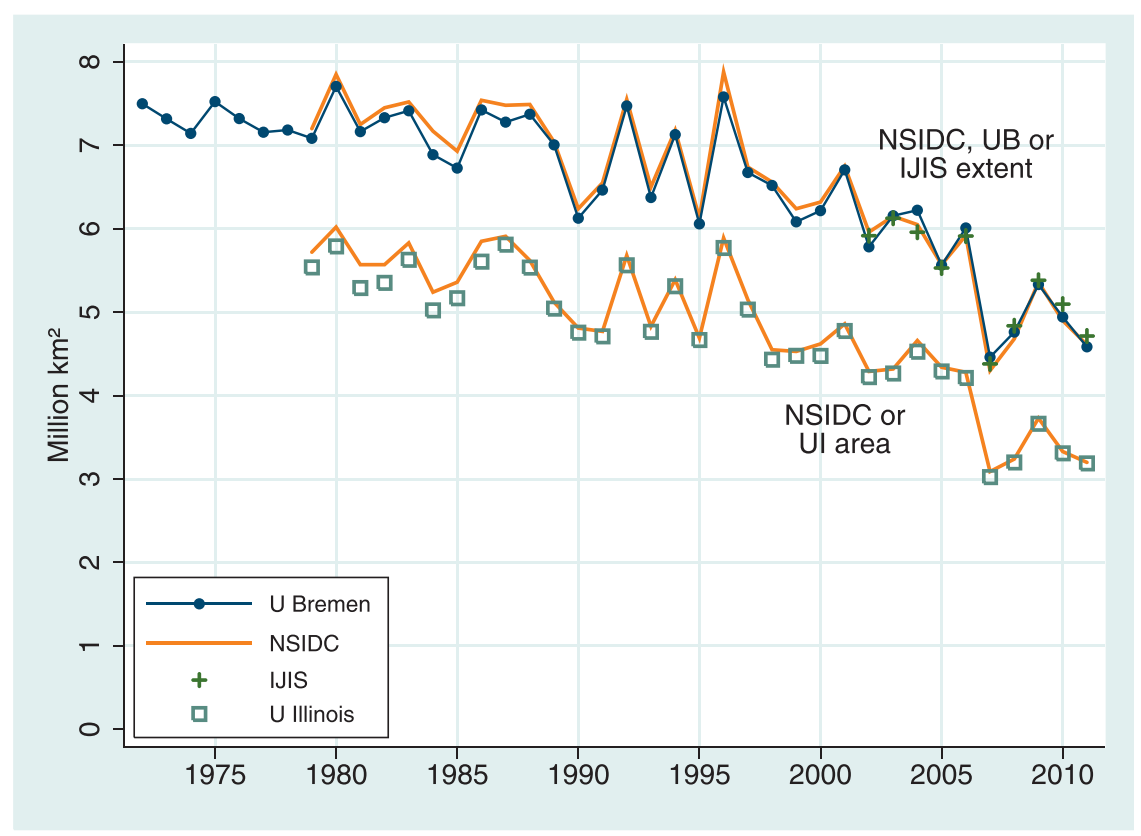

FIG. 2. Mean September extent and area of Arctic sea ice, 1972-2011.

cross sections of the U.S. public whether they thought that "the polar ice caps have gotten larger or smaller in recent years." Although the question is not precisely worded, $77 \%$ in 2006 and $81 \%$ in 2010 answered "smaller" (Hamilton et al. 2012).

Scientists cite the reduction in Arctic sea ice as a symptom of global warming (e.g., Solomon et al. 2007; Richardson et al. 2009; Notz and Marotzke 2012). Outside the channels of scientific communication, individuals and organizations wishing to challenge the reality of global warming have sought to tell the Arctic ice story differently. For example, a widely publicized Heartland Institute report that downplays global warming concerns (Idso and Singer 2009) does not include graphs resembling Fig. 2. Instead, authors of this 2009 report cite a 1999 paper that used data just through 1998. Although the original 1999 researchers had noted a 14\% decline in ice extent over 1978-98, the Heartland Institute authors set this aside to emphasize a shorter time interval, writing that "it could be argued from their data that from 1990/91 onward (to 1998), sea ice area in the Arctic may have actually increased" (Idso and Singer 2009, p. 155, emphasis by Idso and Singer). One has to look closely at the 1991-98 interval in Fig. 2, and ignore later years, to see the interannual variations that inspired this statement.

Another way to overlook the downward trends in Fig. 2 is to focus on time windows different from the 1970s-to-present period of satellite observation. Some authors cite anecdotal accounts of earlier warm periods, or fit sinusoidal curves to data, to argue that warming comes and goes in 60-yr or longer cycles (e.g., Loehle and Scafetta 2011). Alternatively, others have emphasized very short time intervals such as announcing a recovery when ice extent in 2008 and 2009 rose above the historical minimum of 2007 (e.g., Whitehouse, quoted in Jamieson 2010). Even at the short-lived peak of the 2008-09 "recovery," however, late-summer ice area remained well below any observed prior to 2007. As the polar winter approaches each fall, some writers herald the annual refreeze as a recovery (e.g., Booker 2008).

Tenuous though these arguments are, they leave floating in the infosphere suggestions that "Arctic sea ice has recovered." So who believes that claim? Figure 3 breaks down responses to our Arctic ice question by general belief about climate change. Both U.S. and New Hampshire surveys find similar patterns. Nationally, $80 \%$ of those who believe that climate change is happening now, caused mainly by human activities, also know that Arctic ice area has declined. Only $60 \%$ of those who believe climate is changing for natural reasons, and $32 \%$ of those who believe it is not changing, accept this fact. The answer that sea ice area has recovered is chosen by only $5 \%$ of those believing climate is changing now because of humans, $16 \%$ of those who believe current change is natural, and $40 \%$ of those who believe climate is not changing.

A science-literacy explanation for this correlation would be that people believe something other than now/ human because they do not know Arctic ice has declined (along with other facts). A biased-assimilation explanation fits this correlation equally well; however, some 


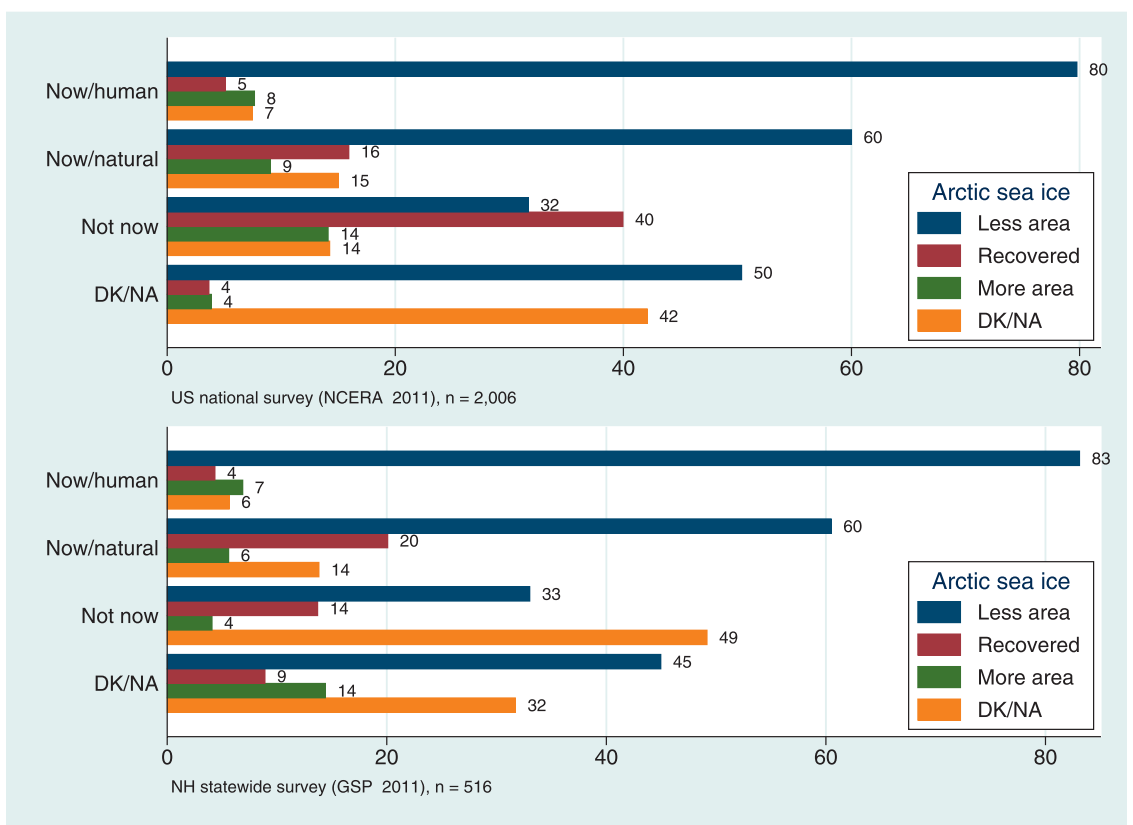

FIG. 3. Late-summer Arctic sea ice area compared with 30 years ago, by personal belief about climate change. Results from (top) national and (bottom) statewide surveys.

people accept tenuous claims, or simply guess that Arctic ice recovered, because that fits better with their belief that humans are not causing change. No doubt both scienceliteracy and biased-assimilation/guessing processes are at work, although one detail in Fig. 3 leans toward bias. Those who say they don't know or express no belief about climate change (DK/NA) are more likely than those who believe climate is not changing to say that Arctic ice has declined, and less likely than either the now/natural or not-now groups to say that Arctic ice has recovered. This detail replicates across both surveys.

\section{Real and perceived carbon dioxide}

Since the nineteenth century, carbon dioxide or $\mathrm{CO}_{2}$ has been recognized as a greenhouse gas in the atmosphere, so called because it is relatively transparent to short- and medium-wavelength radiation (such as incoming ultraviolet and visible light from the sun) but tends to absorb and reradiate longer-wavelength infrared (such as that emitted by Earth's surface). In 1896 Svante Arrhenius, building on work by his colleague Arvid Högbom, first published the hypothesis that rising concentrations of $\mathrm{CO}_{2}$ released by burning of fossil fuels would trap more solar energy within the atmosphere and hence warm the climate. By Högbom's and Arrhenius' reckoning, an anthropogenic doubling of $\mathrm{CO}_{2}$ concentration remained several thousand years in the future (Weart 2008).

Fuel use increased radically over the twentieth century, however. The first accurate series of $\mathrm{CO}_{2}$ measurements, started in 1958, were by 1960 already showing evidence of yearly rise roughly matching that expected from the combustion of fossil fuels (Keeling 1960). The continuous time series of $\mathrm{CO}_{2}$ measurements at Mauna Loa, Hawaii, originated by Charles D. Keeling, subsequently painted a startling picture that helped persuade many scientists to take a closer look at anthropogenic climate change. It has been called "one of the most important geophysical records ever made" (Scripps Institution of Oceanography 2012). Figure 4 graphs the Mauna Loa monthly time series or Keeling curve from 1958 through 2011, together with a companion series from the South Pole since 1980 [Fig. 4 graphs monthly $\mathrm{CO}_{2}$ data archived by the National Oceanic and Atmospheric Administration (2012)]. The South Pole series exhibits different seasonality but follows the same trend.

As with Arctic ice, unscientific claims about carbon dioxide abound. One popular meme claims that carbon dioxide rise is just an artifact of measurement on Mauna Loa, a volcano-although as Fig. 4 illustrates, global trends have been widely confirmed. Another claim concedes the rise but asserts that its cause is volcanic. For example, Plimer (2009) declares that volcanoes emit far more $\mathrm{CO}_{2}$ than humans. Corollaries of this claim state that emissions from one large volcano, or from seafloor vents, dwarf various human sources. But as Terry Gerlach observes in Eos, Trans. Amer. Geophys. Union, such claims flatly contradict the science (Gerlach 2011). Serious estimates of recent global volcanic $\mathrm{CO}_{2}$ emissions, including submarine sources, range from 0.13 to 0.44 gigatons per 


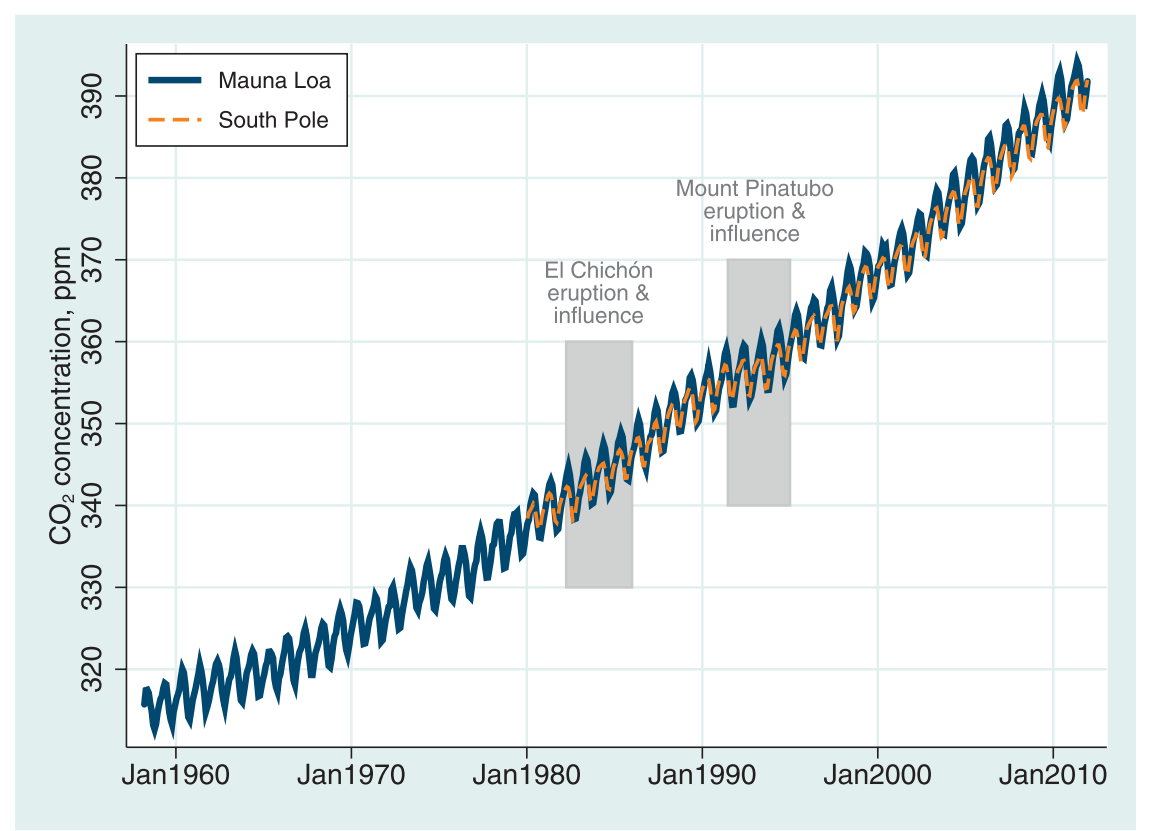

FIG. 4. Monthly $\mathrm{CO}_{2}$ concentration at Mauna Loa (Keeling curve) and South Pole, 1958-2011.

year-around $1 \%$ of the 35 gigatons per year released by human activities. Even the Yellowstone caldera supereruption, which occurred 2 million years ago and would devastate the United States if repeated today, may have released less $\mathrm{CO}_{2}$ than a single year of human activities (Gerlach 2011). Figure 4 visualizes the contrasting scales of recent human and volcanic contributions by shading the dates (plus three years) of El Chichón and Pinatubo eruptions, the two largest in this period. Neither eruption had visible effects on Mauna Loa or South Pole $\mathrm{CO}_{2}$ records, although other data show that their aerosol emissions cooled surface temperatures.

Who does not know about rising $\mathrm{CO}_{2}$ ? Figure 5 breaks down survey responses to our Keeling question by belief about climate change, in the same manner Fig. 3 did with ice. People choosing the now/human answer to Belief CC overwhelmingly know that carbon dioxide concentration is rising. However, only half those answering now/natural accept this, and only a quarter of those answering not now. More than half the NCERA now/natural respondents say that carbon dioxide concentrations are staying about the same. Again, this belief-knowledge correlation might be interpreted as a science-literacy effect (knowledge affects beliefs), but details support a biased-assimilation or biasedguessing (beliefs affect knowledge assimilation) component as well. Respondents expressing no belief about climate change answered as accurately about Keeling as the now/natural respondents-and much better than the not-now group. The superior performance of DK/NA respondents across two questions on two surveys makes sense if misperceptions of Arctic ice and carbon dioxide reflect bias rather than a simple lack of knowledge.

A weaker version of the patterns in Figs. 3 and 5 occurs with responses to the Greenhouse question (not shown). On both U.S. and New Hampshire surveys, the now/ human group most often knows the meaning of greenhouse effect, while the not-now group scores no better than DK/NA respondents. But the relatively weak connection between Greenhouse and Belief CC suggests that knowing the meaning of "greenhouse effect" reflects mainly science literacy and is less subject to biased assimilation or guessing.

Although biased guessing has been mentioned with respect to Arctic ice and Keeling, it probably played a minor role as these two were answered correctly by $60 \%$ to $70 \%$ of respondents. The next section considers two difficult questions on which guessing seems more likely.

\section{Volcanoes and sea level}

Do volcanoes emit more $\mathrm{CO}_{2}$ than humans? Which would raise sea level more if it happened: melting ice in the Himalaya, in Greenland/Antarctica, or on the Arctic Ocean? Our Volcano and Sealevel questions, like other knowledge items in Table 1, involve central and welldiscussed points accepted by contrarian as well as mainstream scientists. Unlike the earlier items they prove difficult for survey respondents to answer, with no more than a third getting each right, and larger fractions admitting they don't know. Indeed there is no reason to 


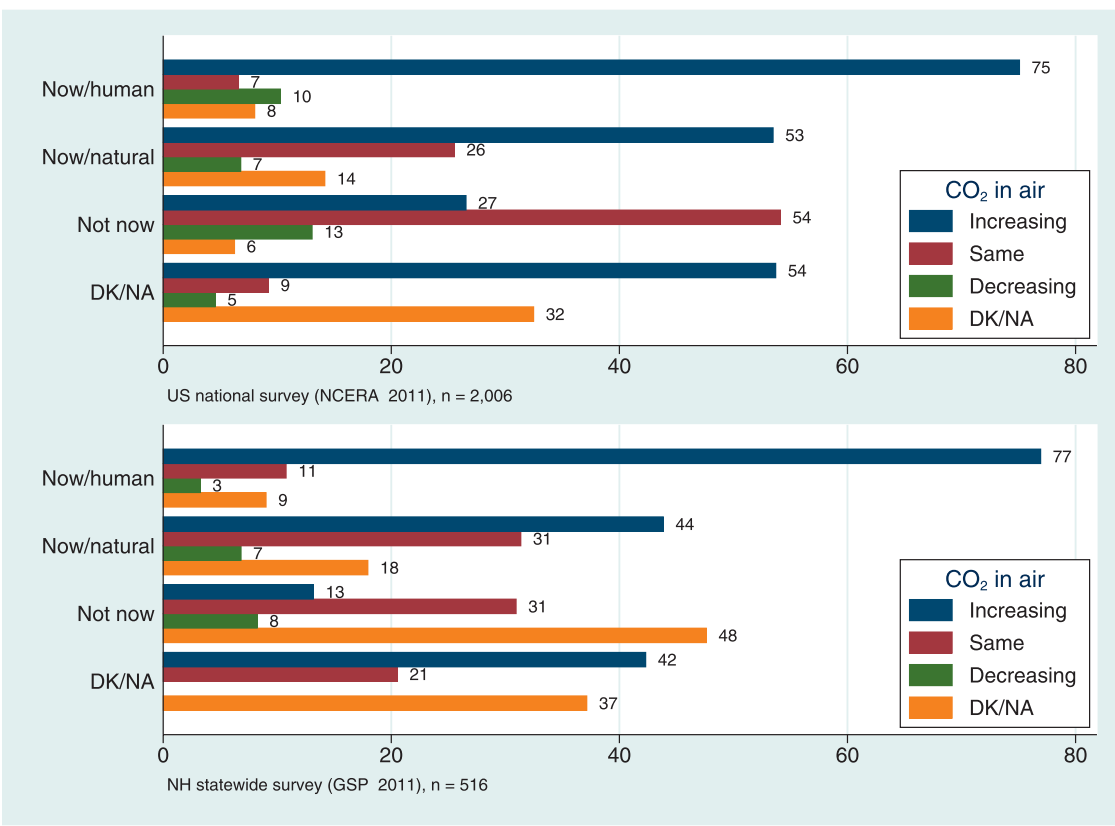

FIG. 5. Atmosphere $\mathrm{CO}_{2}$ concentration in recent decades, by personal belief about climate change. Results from (top) national and (bottom) statewide surveys.

expect that most people should know the answers. One involves some exposure to scientific discussions, because the quantities involved are not common knowledge. The other requires a geographical sense of the relative mass of Greenland/Antarctic ice sheets compared with Himalayan glaciers, or why melting sea ice would have only minor impacts on sea level. Perhaps it is surprising that more than $60 \%$ think they do know each answer, although about half of those who think so are mistaken.

Thus, there is probably more guessing on the answers, mixed with biased assimilation and science knowledge. The net effects of these influences are not random, however. Figure 6 breaks down Volcano and Sealevel responses by climate beliefs.

Correct answers to Volcano occur most often (45\%) among those who believe humans are changing the climate. One specific wrong answer shows the opposite pattern: $6 \%$ of now/human, $24 \%$ of now/natural, and $33 \%$ of not-now respondents think that in recent decades, volcanoes have released much more $\mathrm{CO}_{2}$ than humans. As with "Arctic ice recovery," the "volcanoes emit more $\mathrm{CO}_{2}$ " claim has been publicized by authoritative-sounding sources (e.g., Plimer 2009) as a talking point against anthropogenic climate change, making it a good candidate for biased assimilation.

Response choices for the Sealevel question, on the other hand, include no talking points. Like a more difficult counterpart to our Greenhouse question, Sealevel invokes science literacy, and holding a particular belief about climate provides little guidance on which Sealevel answer to guess. Even so, now/human respondents most often got it right $(36 \%)$, followed by the now/natural $(27 \%)$ and don't know (14\%) groups. That pattern on a difficult question without cues for guessing highlights the science literacy contribution. On the other hand a high proportion of DK/NA responses to Sealevel among people who do not believe climate is changing (73\%) might signify their rejection of the premise that any of these melting-ice events could happen.

In summary, respondents who believe that humans are changing the climate answer more accurately on all of the knowledge questions. The content of two questions (Greenhouse and Sealevel) appears mainly to assess science literacy. Content of the other three (Arctic ice, Keeling and Volcano) has more obvious connections to particular beliefs about climate, so responses could reflect a combination of science-literacy with biased-assimilation or biased-guessing effects. Details of response patterns support this distinction. The next section examines how demographic factors, political outlook, and climate beliefs together predict knowledge-question responses.

\section{Predictors of climate beliefs and knowledge}

Figure 1 charts demographic correlates of climatechange beliefs, while Figs. 3, 5, and 6 display how beliefs correlate with responses to climate-change knowledge questions. Table 2 extends these analyses by estimating the net and combined effects of demographic variables as 


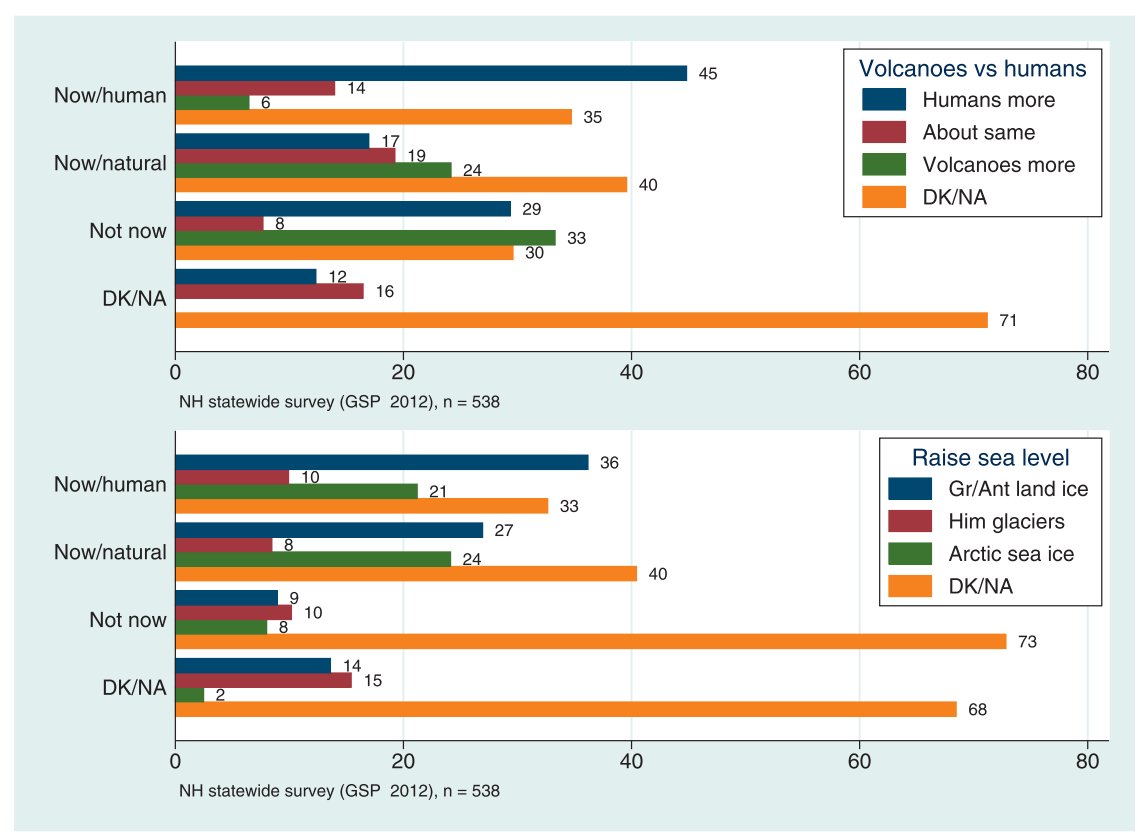

FIG. 6. (top) Have volcanoes or humans released more $\mathrm{CO}_{2}$ over past few decades, and (bottom) what would do the most to raise sea level if it happened, by personal belief about climate change. Results from NH statewide survey.

predictors of belief, and of both demographics and belief as predictors of response to knowledge questions. The table shows results from weighted multinomial logit regressions of climate change belief and knowledge responses on six possible predictors including Age in years; Gender (1 female, 0 male); Education (a 4-point scale, centered to 0 mean); political Party (Democrat, Independent, or Republican, also centered); and the interaction term Party $\times$ Education. Centering Party and Education improves the efficiency of parameter estimates and simplifies interpretation of main effects, which then describe the effect of each variable when the other is at its mean. Mean Party corresponds roughly to Independent, and mean Education to technical school or some college. The sixth possible predictor in Table 2 is a dummy variable (Anthro CC) indicating belief that climate change is happening now, caused mainly by human activities.

Two different models are estimated for each of the three knowledge questions in Table 2 (but only one for the Belief $\mathrm{CC}$ question). The left-hand column in each pair gives the regression of knowledge-question responses on the five background predictors (Age, Gender, Education, Party, and Party $\times$ Education) just mentioned. These are standard predictors used in studies concerning the social bases of environmental concern (e.g., Jones and Dunlap 1992; Van Liere and Dunlap 1980), extensively validated across many previous studies but tested here as possible predictors of the new climate-knowledge questions. The right-hand column in each pair gives a model with the same predictors plus one more: belief that humans are changing the climate (Anthro CC). These second models in each pair reflect a biased-assimilation hypothesis: beliefs affect the acquisition of information, and especially of specific information congenial to more general beliefs. Cross-sectional data cannot definitively test causal order, but details of response patterns support that interpretation.

Multinomial logit regression, designed for categorical dependent variables, models the odds favoring a particular outcome (such as a now/natural, not now, or DK/ NA response to the Belief CC question) in contrast to a base outcome (such as now/human). ${ }^{2}$ Relative risk ratios in the Belief $\mathrm{CC}$ column describe the multiplicative effect of a unit increase in each predictor on the odds of selecting a particular Belief CC response instead

\footnotetext{
${ }^{2}$ Multinomial logit models are preferred for dependent variables with multiple unordered categories. Some of the knowledge questions have categories that sound ordinal, such as less, same, or more $\mathrm{CO}_{2}$, so alternative models such as ordered logit might be considered. Empirically, however, our responses do not follow ordinal patterns, as results in Tables 2 and 3 clearly show. That is, the response categories may be ordinal in terms of physical quantities they reference, but not in terms of relationships with predictors in the models. Brant tests confirm this impression, and lead to rejection of the parallelregression hypothesis for ordered-logit models corresponding to 13 of the 18 regressions in this paper if we simply set DK/NA responses aside, and to 18 out of 18 if we keep those responses in with ordinal coding instead. Finally, the DK/NA responses, which are most sensibly set aside for an ordinal analysis, hold key information about who knows what, as revealed by the multinomial analysis.
} 
TABLE 2. Predictors of personal belief (Belief CC) and wrong answers to three factual questions (Arctic ice, Keeling, and Greenhouse) about climate. Relative risk ratios from weighted multinomial logit regressions using U.S. national survey data; statistically significant effects in bold. For each of the three knowledge questions, two models are shown: without and with the inclusion of Anthro CC belief among the predictors.

\begin{tabular}{|c|c|c|c|c|c|c|c|}
\hline \multicolumn{8}{|c|}{ Dependent variable } \\
\hline Predictor & Belief CC & \multicolumn{2}{|c|}{ Arctic ice } & \multicolumn{2}{|c|}{ Keeling } & \multicolumn{2}{|c|}{ Greenhouse } \\
\hline (Base) & Now/human & \multicolumn{2}{|c|}{ Less area } & \multicolumn{2}{|c|}{ Increasing } & \multicolumn{2}{|c|}{ Heat trapping } \\
\hline & Now/natural & \multicolumn{2}{|c|}{ Recovered } & \multicolumn{2}{|c|}{ Same } & \multicolumn{2}{|c|}{ Ozone hole } \\
\hline Age & $1.01^{\mathrm{a}}$ & $1.02^{b}$ & $1.01^{\mathrm{a}}$ & $1.01^{\mathrm{a}}$ & 1.01 & 1.01 & 1.01 \\
\hline Gender $(F)$ & 0.87 & 0.76 & 0.79 & 1.28 & 1.39 & $1.43^{\mathrm{a}}$ & $1.43^{\mathrm{a}}$ \\
\hline Education & $0.82^{b}$ & 0.84 & 0.90 & $0.76^{b}$ & $0.81^{\mathrm{a}}$ & $0.75^{\mathrm{c}}$ & $0.75^{\mathrm{c}}$ \\
\hline Party (D/I/R) & $2.24^{\mathrm{c}}$ & $2.36^{c}$ & $1.89^{c}$ & $1.67^{\mathrm{c}}$ & $1.26^{\mathrm{a}}$ & 0.84 & $0.83^{\mathrm{a}}$ \\
\hline Party $\times$ educ & $1.26^{b}$ & 1.06 & 0.99 & 1.11 & 1.02 & 0.96 & 0.95 \\
\hline Anthro CC & - & - & $0.25^{\mathrm{c}}$ & - & $0.17^{\mathfrak{c}}$ & - & 0.92 \\
\hline \multirow[t]{2}{*}{ Constant } & 0.55 & 0.07 & 0.13 & 0.13 & 0.31 & 0.28 & 0.29 \\
\hline & Not now & \multicolumn{2}{|c|}{ More area } & \multicolumn{2}{|c|}{ Decreasing } & \multicolumn{2}{|c|}{ Pavement } \\
\hline Age & $1.02^{\mathrm{c}}$ & 1.00 & 1.00 & 1.00 & 1.00 & 1.01 & 1.01 \\
\hline Gender $(\mathrm{F})$ & 0.69 & 1.21 & 1.22 & 1.12 & 1.14 & 0.97 & 0.99 \\
\hline Education & $0.62^{\mathrm{a}}$ & $0.70^{\mathrm{c}}$ & $0.71^{b}$ & 0.84 & 0.85 & $0.61^{\mathrm{c}}$ & $0.63^{\mathrm{c}}$ \\
\hline Party (D/I/R) & $3.61^{\mathrm{c}}$ & 1.02 & 0.96 & 1.05 & 1.01 & 0.95 & 0.87 \\
\hline Party $\times$ educ & $1.56^{\mathrm{a}}$ & 1.12 & 1.10 & 1.21 & 1.20 & 0.97 & 0.94 \\
\hline Anthro CC & - & - & 0.70 & - & 0.80 & - & 0.62 \\
\hline \multirow[t]{2}{*}{ Constant } & 0.03 & 0.10 & 0.12 & 0.14 & 0.16 & 0.07 & 0.09 \\
\hline & DK/NA & \multicolumn{2}{|c|}{ DK/NA } & \multicolumn{2}{|c|}{ DK/NA } & \multicolumn{2}{|c|}{ DK/NA } \\
\hline Age & $1.03^{\mathrm{c}}$ & $1.02^{b}$ & $1.01^{\mathrm{a}}$ & $1.03^{\mathrm{c}}$ & $1.03^{\mathrm{c}}$ & $1.04^{c}$ & $1.04^{\mathrm{c}}$ \\
\hline Gender $(\mathrm{F})$ & 1.25 & $2.09^{c}$ & $2.16^{c}$ & $4.01^{c}$ & $4.20^{c}$ & $2.36^{c}$ & $2.40^{c}$ \\
\hline Education & $0.65^{b}$ & $0.72^{b}$ & $0.75^{\mathrm{a}}$ & $0.72^{\mathrm{c}}$ & $0.75^{b}$ & $0.62^{\mathrm{c}}$ & $0.64^{c}$ \\
\hline Party (D/I/R) & $1.69^{c}$ & $1.52^{\mathrm{c}}$ & $1.28^{\mathrm{a}}$ & $1.39^{b}$ & 1.18 & 0.89 & 0.80 \\
\hline Party $\times$ educ & 1.21 & $1.30^{\mathrm{a}}$ & 1.26 & 1.07 & 1.02 & 1.16 & 1.13 \\
\hline Anthro CC & - & - & $0.36^{c}$ & - & $0.40^{\mathrm{c}}$ & - & $0.56^{\mathrm{a}}$ \\
\hline Constant & 0.01 & 0.04 & 0.07 & 0.02 & 0.03 & 0.02 & 0.03 \\
\hline Sample size & 1714 & \multicolumn{2}{|c|}{1714} & \multicolumn{2}{|c|}{1714} & \multicolumn{2}{|c|}{1714} \\
\hline
\end{tabular}

${ }^{\mathrm{a}} p<0.05$.

${ }^{\mathrm{b}} p<0.01$

${ }^{\mathrm{c}} p<0.001$ (from linearized $t$ tests; results for constant terms not shown).

of now/human, if other predictor values remain the same. A relative risk ratio below 1 means the odds favoring a particular response over the base response are decreased with each unit rise in the predictor, so ratios below 1 correspond to "negative" effects if these were transformed into additive models. Conversely, relative risk ratios above 1 mean the odds favoring that response increase with each unit rise in the predictor; they correspond to "positive" effects in an additive model.

We see that older, less educated or Republican respondents are more likely to believe climate change is happening now but for natural reasons, or not happening now, or to give no answer-anything but changing now because of human activities. For example, other things being equal the odds of a Republican with average education responding that climate is not changing now (rather than changing now due to humans) are 261\% higher (multiplied by 3.61) compared with those of an Independent, which in turn are higher than those of a Democrat. The odds that someone of Independent political persuasion responds that climate is not changing now decrease by $18 \%$ (are multiplied by 0.82 ) with each oneunit rise in education. The significant Party $\times$ Education interactions mean that the odds of choosing now/natural or not now instead of now/human decrease steeply with education among self-identified Democrats, decrease less steeply with education among Independents, and are almost unrelated to education among Republicans. Figure 7 depicts this interaction effect graphically. The adjusted marginal plot shows probabilities calculated by the first model in Table 2, controlling for other variables in the model (see Mitchell 2012 for details on adjusted 


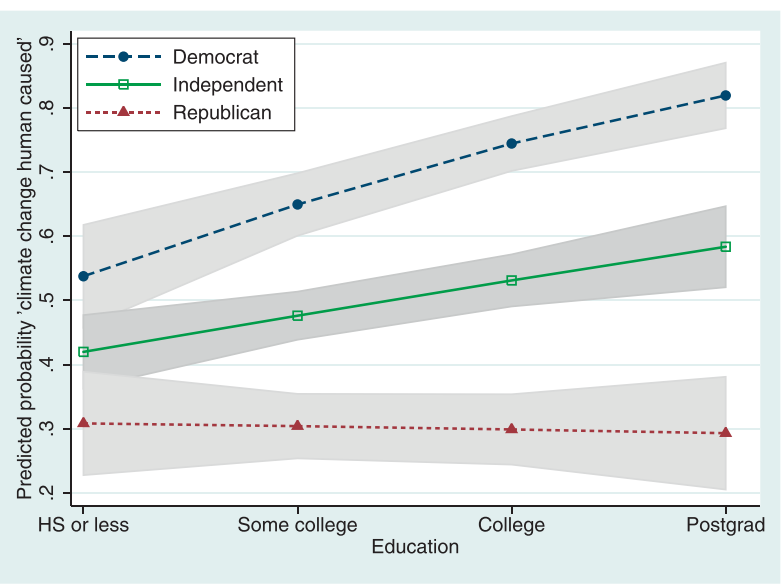

FIG. 7. Predicted probability of "climate change happening now, caused mainly by human activities" response, illustrating the interaction of education and political identity. Probabilities calculated from the first model in Table 2, with adjustment for other predictors in the model.

marginal plots; introduced more briefly in Hamilton 2013). Analogous interactions have been detected in many other studies (reviewed in McCright and Dunlap 2011; see Hamilton 2008, 2011a or Hamilton et al. 2012 for graphic examples).

The remaining columns in Table 2 present two models for each of three knowledge questions. One employs demographic and political predictors only, and a second includes belief in anthropogenic climate change (Anthro $\mathrm{CC}$, indicating a now/human response to Belief $\mathrm{CC}$ ) among the predictors. Correct answers form the base categories for each question, so the relative risk ratios can be read as predicting the various wrong answers. For example, the response that late-summer Arctic sea ice has recovered to about the same area it had 30 years ago is more popular among older respondents, Republicans, and net of demographics and politics, among people who do not believe human activities are changing the climate. Republicans have roughly $89 \%$ higher odds than Independents and $257 \%$ higher odds than Democrats (multiplied by $1.89^{2}=3.57$ ) of saying that Arctic ice has recovered instead of declined. People who believe climate change is happening now because of humans have $75 \%$ lower odds (multiplied by 0.25 ) of saying that ice recovered instead of declined. The equally wrong but not media-promoted assertion that Arctic ice area has increased is favored only by less educated respondents.

A similar pattern occurs with the carbon dioxide trends question (Keeling). The response that $\mathrm{CO}_{2}$ concentrations are staying about the same instead of increasing is favored by Republican respondents (odds $26 \%$ higher than Independents, 59\% higher than Democrats). This $\mathrm{CO}_{2}$-same response has $83 \%$ lower odds among people who believe humans that are changing the climate. The more extreme response that $\mathrm{CO}_{2}$ levels are decreasing shows no significant demographic or political predictors.

Greenhouse predictors exhibit a somewhat different pattern, supporting the impression that this question taps science literacy, with less potential for biased assimilation or guessing. All of the incorrect responses to Greenhouse become less likely with increasing Education. Weaker but significant party and gender effects (Democrat and female odds higher) occur on the "ozone hole" response.

Odds favoring don't know or no-answer responses to the three knowledge questions are higher among older, less educated, and female respondents. Party raises the odds of DK/NA responses on the Arctic ice and Keeling items but not on Greenhouse. Anthro CC lowers the odds of DK/NA responses on all three knowledge questions, but does so most strongly for Arctic ice and Keeling. These DK/NA patterns further support interpretation of Greenhouse responses mainly reflecting science literacy, whereas Arctic ice and Keeling responses combine science-literacy with biased-assimilation or biased-guessing effects.

The first seven columns of Table 3 replicate Table 2 models using New Hampshire instead of national data. In the New Hampshire surveys too, Belief CC is predicted by Age, Gender, Education, Party, and the interaction of Party $\times$ Education. The direction and relative strength of these effects are similar across U.S. and state surveys, further encouragement that New Hampshire results are reasonably representative, and the common findings from both are robust. Predictors of Arctic ice, Keeling, and Greenhouse responses also show many similarities, including consistent Party and Anthro CC effects on Arctic ice and Keeling, but not on Greenhouse. The odds of wrong answers on all three become lower with rising Education.

The last four columns in Table 3 model responses to the difficult Volcano and Sealevel questions, tested on one New Hampshire survey. Education lowers the odds of wrong and DK/NA responses to both questions, demonstrating a science-literacy effect. Biased-assimilation or guessing effects appear likely, particularly for Volcano. Belief that humans cause climate change much reduces odds of thinking that volcanoes released more $\mathrm{CO}_{2}$ than humans. To a lesser degree Anthro CC also reduces the odds of thinking volcanoes released the same amount as humans, or of saying I don't know. Sealevel responses show weaker and less consistent effects from political party or climate change belief. These patterns fit with an expectation that bias would have more influence on Volcano responses than on Sealevel, because the latter lacks belief-related cues. 
TABLE 3. Predictors of personal belief (Belief CC) and wrong answers to five factual questions (Arctic ice, Keeling, Greenhouse, Volcano, and Sealevel) about climate. Relative risk ratios from weighted multinomial logit regressions with New Hampshire survey data; statistically significant effects in bold. For each of the five knowledge questions, two models are shown: without and with the inclusion of Anthro CC belief among the predictors.

\begin{tabular}{|c|c|c|c|c|c|c|c|c|c|c|c|}
\hline \multicolumn{12}{|c|}{ Dependent variable } \\
\hline Predictor & Belief CC & \multicolumn{2}{|c|}{ Arctic ice } & \multicolumn{2}{|c|}{ Keeling } & \multicolumn{2}{|c|}{ Greenhouse } & \multicolumn{2}{|c|}{ Volcano } & \multicolumn{2}{|c|}{ Sealevel } \\
\hline \multirow[t]{2}{*}{ (Base) } & Now/human & \multicolumn{2}{|c|}{ Less area } & \multicolumn{2}{|c|}{ Increasing } & \multicolumn{2}{|c|}{ Heat trapping } & \multicolumn{2}{|c|}{ Humans } & \multicolumn{2}{|c|}{ Antarctic } \\
\hline & Now/natural & \multicolumn{2}{|c|}{ Recovered } & \multicolumn{2}{|c|}{ Same } & \multicolumn{2}{|c|}{ Ozone hole } & \multicolumn{2}{|c|}{ Same } & \multicolumn{2}{|c|}{ Himalaya } \\
\hline Age & $1.02^{\mathrm{a}}$ & 1.01 & 1.00 & 1.01 & 1.00 & $1.02^{\mathrm{a}}$ & $1.02^{a}$ & 1.01 & 1.01 & 0.98 & 0.98 \\
\hline Gender $(\mathrm{F})$ & $0.60^{\mathrm{a}}$ & 0.60 & 0.70 & 1.05 & 1.28 & $1.99^{\mathrm{a}}$ & $2.01^{\mathrm{a}}$ & 0.98 & 1.05 & $3.43^{b}$ & $3.41^{\mathrm{b}}$ \\
\hline Education & $0.80^{\mathrm{a}}$ & 0.86 & 0.94 & $0.71^{c}$ & $0.75^{\mathrm{c}}$ & $0.72^{\mathrm{a}}$ & $0.72^{\mathrm{a}}$ & $0.69^{c}$ & $0.69^{c}$ & $0.44^{\mathrm{a}}$ & $0.45^{\mathrm{a}}$ \\
\hline Party (D/I/R) & $3.12^{\mathrm{a}}$ & $2.31^{\mathrm{a}}$ & $1.68^{c}$ & $1.89^{a}$ & 1.33 & 1.00 & 0.98 & 1.29 & 1.01 & $1.60^{c}$ & 1.55 \\
\hline Party $\times$ educ & $1.32^{b}$ & 0.89 & 0.80 & $0.72^{\mathrm{c}}$ & $0.63^{b}$ & 1.14 & 1.04 & 0.97 & 0.89 & 1.37 & 1.36 \\
\hline Anthro CC & - & - & $0.22^{b}$ & - & $0.19^{\mathrm{a}}$ & - & 0.92 & - & $0.31^{b}$ & - & 0.87 \\
\hline \multirow[t]{2}{*}{ Constant } & 0.22 & 0.09 & 0.25 & 0.18 & 0.53 & 0.15 & 0.16 & 0.28 & 0.63 & 0.39 & 0.42 \\
\hline & Not now & \multicolumn{2}{|c|}{ More area } & \multicolumn{2}{|c|}{ Decreasing } & \multicolumn{2}{|c|}{ Pavement } & \multicolumn{2}{|c|}{ Volcanoes } & \multicolumn{2}{|c|}{ Sea ice } \\
\hline Age & $1.03^{\mathrm{a}}$ & 1.02 & 1.02 & 1.00 & 1.00 & $1.04^{\mathrm{a}}$ & $1.04^{a}$ & 1.02 & 1.01 & 1.00 & 1.00 \\
\hline Gender $(\mathrm{F})$ & 0.69 & 0.58 & 0.59 & $3.48^{\mathrm{c}}$ & $4.00^{c}$ & 0.93 & 1.02 & 0.80 & 0.91 & 1.71 & 1.74 \\
\hline Education & $0.53^{\mathrm{a}}$ & $0.49^{\mathrm{a}}$ & $0.50^{\mathrm{a}}$ & 0.84 & 0.87 & $.49^{\mathrm{a}}$ & $0.51^{\mathrm{a}}$ & $0.69^{\mathrm{c}}$ & 0.72 & 0.82 & 0.83 \\
\hline Party (D/I/R) & $5.59^{\mathrm{a}}$ & 0.89 & 0.93 & $2.38^{b}$ & $1.95^{\mathrm{c}}$ & $1.61^{\mathrm{a}}$ & 1.34 & $2.33^{\mathrm{a}}$ & 1.52 & 1.06 & 0.99 \\
\hline Party $\times$ educ & $1.87^{\mathrm{a}}$ & 0.66 & 0.68 & 1.22 & 1.17 & 1.11 & 1.07 & 1.10 & 0.96 & $1.44^{\mathrm{c}}$ & $1.42^{\mathrm{c}}$ \\
\hline Anthro CC & - & - & 1.14 & - & 0.39 & - & $0.47^{\mathrm{b}}$ & - & $0.15^{\mathrm{a}}$ & - & 0.75 \\
\hline \multirow[t]{2}{*}{ Constant } & 0.01 & 0.02 & 0.02 & 0.03 & 0.52 & 0.01 & 0.02 & 0.16 & 0.56 & 0.44 & 0.52 \\
\hline & DK/NA & \multicolumn{2}{|c|}{ DK/NA } & \multicolumn{2}{|c|}{ DK/NA } & \multicolumn{2}{|c|}{ DK/NA } & \multicolumn{2}{|c|}{ DK/NA } & \multicolumn{2}{|c|}{ DK/NA } \\
\hline Age & $1.04^{\mathrm{a}}$ & 0.99 & 0.99 & 1.00 & 0.99 & $1.05^{\mathrm{a}}$ & $1.04^{a}$ & $1.02^{b}$ & 1.02 & $1.02^{\mathrm{c}}$ & $1.02^{\mathrm{c}}$ \\
\hline Gender $(\mathrm{F})$ & $0.51^{\mathrm{b}}$ & 1.08 & 1.26 & 1.51 & 1.84 & $2.03^{a}$ & $2.30^{\mathrm{a}}$ & $1.84^{\mathrm{c}}$ & $1.99^{b}$ & $2.91^{\mathrm{a}}$ & $\mathbf{3 . 0 3}^{\mathrm{a}}$ \\
\hline Education & $0.81^{\mathrm{c}}$ & 0.77 & 0.83 & 0.83 & 0.87 & $0.56^{\mathrm{a}}$ & $0.58^{\mathrm{a}}$ & 0.86 & 0.87 & $0.71^{b}$ & $0.72^{\mathrm{c}}$ \\
\hline Party (D/I/R) & $2.38^{a}$ & $2.30^{\mathrm{a}}$ & $1.70^{c}$ & $1.68^{b}$ & 1.21 & 1.22 & 0.94 & $1.50^{b}$ & 1.19 & 1.28 & 1.10 \\
\hline Party $\times$ educ & $1.39^{b}$ & 1.01 & 0.93 & 0.98 & 0.89 & 1.06 & 1.00 & 1.08 & 1.00 & 1.04 & 1.00 \\
\hline Anthro CC & - & - & $0.24^{\mathrm{a}}$ & - & $0.22^{\mathrm{a}}$ & - & $0.32^{\mathrm{a}}$ & - & $0.32^{\mathrm{a}}$ & - & $0.53^{\mathrm{c}}$ \\
\hline Constant & 0.02 & 0.18 & 0.47 & 0.20 & 0.54 & 0.01 & 0.02 & 0.26 & 0.58 & 0.23 & 0.35 \\
\hline Sample size & 1972 & & & & & & & & & & \\
\hline
\end{tabular}

${ }^{\mathrm{a}} p<0.001$ (from linearized $t$ tests; results for constant terms not shown).

${ }^{\mathrm{b}} p<0.01$.

${ }^{c} p<0.05$.

\section{Discussion}

Science knowledge correlates with beliefs about climate change, but the causality is complex. On one hand, from previous research we have good evidence for knowledge shaping beliefs. Science literacy defined by a quiz of nonclimate knowledge questions (e.g., is an electron smaller than an atom?) generally predicts concern about climate change, even controlling for demographics, education and other knowledge indicators. The relationship is moderated by ideology, however, so the science-literacy effect is stronger among self-identified moderates and liberals, but weak or even negative among the most conservative (Hamilton et al. 2012). This plausibly reflects biased assimilation, through which some scientifically literate but ideologically motivated respondents selectively acquire information that reinforces their beliefs. Such explanations in turn imply a second kind of information, not belief-neutral background but more specific details that seem to favor particular beliefs. ${ }^{3} \mathrm{Al}-$ though science knowledge including those specific details influences beliefs, causality can operate in the opposite direction as well, with beliefs filtering the assimilation of obviously belief-relevant knowledge.

Both directions operate with the variables studied here. Knowledge questions analyzed in this paper are more detailed than most survey items, but vary in how

\footnotetext{
${ }^{3}$ From a scientific viewpoint, a great deal of background information should be relevant to beliefs about climate. Nonscientists, however, will see some of the connections more clearly than others.
} 
obviously particular answers connect with specific beliefs about climate. The greenhouse effect definition, or which ice could most affect sea level, appear to represent background knowledge not obviously favoring or guessable from a specific climate belief. Empirically supporting this view, both are best predicted from education, with weak or absent effects from partisanship and beliefs. Respondents who accept anthropogenic climate change could more accurately answer both questions, and in this respect show higher science literacy.

In contrast, response choices for questions about trends in Arctic sea ice and carbon dioxide, or whether humans released more carbon dioxide than volcanoes, more obviously imply something about change. People who do not believe that humans are changing the climate find the scientific answers to these questions less appealing. They tend to prefer nonscientific alternatives such as "ice recovered" or "volcanoes more" that have received some media and Internet publicity-evidence for biased assimilation. Even without knowing the alternative claims, respondents' beliefs provide them with cues about which answers to choose. If one believes that climate is not changing, then probably the ice is not melting. Or, if climate is changing but humans are not the cause, then possibly volcanoes are to blame. Thus, although scientific knowledge about these facts no doubt affects climate beliefs, the questions' internal logic and survey data analysis both argue that in these cases, beliefs also affect knowledge.

Science education and outreach efforts commonly aim to communicate basic information that underlies scientific conclusions. An information-to-conclusions ordering follows the natural logic of science, but it fares less well with public opinion on politicized topics where biased assimilation works in the opposite direction. Even well-established observations may be discounted in favor of ideologically more palatable claims available to anyone with television or an Internet connection. Where science communication encounters this roadblock, an alternative strategy could more directly address prevalent misinformation: At an early stage, raise the questions and discuss evidence regarding popular misconceptions such as "Arctic ice has recovered" or "volcanoes emit more $\mathrm{CO}_{2}$." Some science-based websites and outreach activities have been pioneering this approach, with encouraging success. The phrase "teach the controversy" has typically been identified with attacks against evolution in schools, but for the severely polarized public discourse on climate it might be constructively repurposed.

Acknowledgments. This research has been supported by grants from the Ford Foundation and the National Science Foundation (New Hampshire EPSCoR
EPS-1101245), with additional support from the Carsey Institute and the Sustainability Institute at the University of New Hampshire. Both the NCERA and Granite State surveys were conducted by the Survey Center at the University of New Hampshire. Colleagues including Tom Safford, Curt Grimm, Jessica Ulrich, Cameron Wake, and David Moore contributed to the survey design.

\section{REFERENCES}

American Association for the Advancement of Science, cited 2007: AAAS board releases new statement on climate change. [Available online at http://www.aaas.org/news/releases/2007/ 0218am_statement.shtml.]

Booker, C., 2008: So it appears that Arctic ice isn't vanishing after all. The Telegraph, 3 February. [Available online at http://www. telegraph.co.uk/news/uknews/1577399/Christopher-BookersNotebook.html.]

Borick, C. P., and B. G. Rabe, 2010: A reason to believe: Examining the factors that determine individual views on global warming. Soc. Sci. Q., 91, 777-800.

Bostrom, A., M. Granger Morgan, B. Fischhoff, and D. Read, 1994: What do people know about global climate change? Part 1: Mental models. Risk Anal., 14, 959-970.

Brulle, R. J., J. Carmichael, and J. C. Jenkins, 2012: Shifting public opinion on climate change: An empirical assessment of factors influencing concern over climate change in the U.S., 20022010. Climatic Change, 114, 169-188.

Corner, A., L. Whitmarsh, and D. Xenias, 2011: Uncertainty, scepticism and attitudes towards climate change: Biased assimilation and attitude polarisation. Climatic Change, 114, 463-478, doi:10.1007/s10584-012-0424-6.

Darmofal, D., 2005: Elite cues and citizen disagreement with expert opinion. Polit. Res. Q., 58, 381-395.

Dunlap, R. E., and A. M. McCright, cited 2008: A widening gap: Republican and Democratic views on climate change. Environment, September/October. [Available online at http://www. environmentmagazine.org/Archives/Back\%20Issues/SeptemberOctober\%202008/dunlap-full.html.]

Durner, G. M., and Coauthors, 2009: Predicting 21st-century polar bear habitat distribution from climate models. Ecol. Monogr., 29, 25-58.

England, J. H., T. R. Lakeman, D. S. Lemmen, J. M. Bednarski, T. G. Stewart, and D. J. A. Evans, 2008: A millennial-scale record of Arctic Ocean sea ice variability and the demise of the Ellesmere Island ice shelves. Geophys. Res. Lett., 35, L19502, doi:10.1029/2008GL034470.

Gerlach, T., 2011: Volcanic versus anthropogenic carbon dioxide. Eos, Trans. Amer. Geophys. Union, 92, 201-208.

Hamilton, L. C., 2008: Who cares about polar regions? Results from a survey of U.S. public opinion. Arct. Antarct. Alp. Res., 40, 671-678.

, 2011a: Education, politics and opinions about climate change: Evidence for interaction effects. Climatic Change, 104, 231-242.

_ 2011b: Climate change: Partisanship, understanding and public opinion. Carsey Institute, University of New Hampshire Issue Brief 26, 6 pp.

_ 2013: Statistics with Stata, Version 12. Brooks/Cole, in press. , and B. D. Keim, 2009: Regional variation in perceptions about climate change. Int. J. Climatol., 29, 2348-2352. 
__ M. J. Cutler, and A. Schaefer, 2012: Public knowledge and concern about polar-region warming. Polar Geogr., 35, $155-168$.

Idso, C., and S. F. Singer, 2009: Climate Change Reconsidered. Heartland Institute, $880 \mathrm{pp}$.

Institute of Environmental Physics, cited 2011: Daily updated AMSR-E sea ice maps. University of Bremen. [Available online at http://www.iup.uni-bremen.de:8084/amsr/.]

Jamieson, A., 2010: Arctic ice increased during freezing winter Telegraph, 4 April. [Available online at http://www.telegraph. co.uk/earth/environment/climatechange/7552782/Arctic-iceincreased-during-freezing-winter.html.]

Japan Aerospace Exploration Agency, cited 2011: Arctic sea-ice monitor. [Available online at http://www.ijis.iarc.uaf.edu/en/ home/seaice_extent.htm.]

Jones, R. E., and R. E. Dunlap, 1992: The social bases of environmental concern: Have they changed over time? Rural Sociol., 57, 28-47.

Kahan, D. M., H. Jenkins-Smith, and D. Braman, 2011a: Cultural cognition of scientific consensus. J. Risk Res., 14, 147-174.

_, M. Wittlin, E. Peters, P. Slovic, L. L. Ouellette, D. Braman, and G. N. Mandel, 2011b: The tragedy of the risk-perception commons: Culture conflict, rationality conflict, and climate change. Temple University Legal Studies Research Paper 201126, 31 pp. [Available online at http://ssrn.com/abstract=1871503.]

Keeling, C. D., 1960: The concentration and isotopic abundances of carbon dioxide in the atmosphere. Tellus, 12, 200-203.

Kinnard, C., C. M. Zdanowicz, R. M. Koerner, and D. A. Fisher, 2008: A changing Arctic seasonal ice zone: Observations from 1870-2003 and possible oceanographic consequences. Geophys. Res. Lett., 35, L02507, doi:10.1029/2007GL032507.

- - D. A. Fisher, E. Isaksson, A. D. Verna, and L. G. Thompson, 2011: Reconstructed changes in Arctic sea ice over the past 1,450 years. Nature, 479, 509-512.

Krosnick, J. A., A. L. Holbrook, and P.S. Visser, 2000: The impact of the fall 1997 debate about global warming on American public opinion. Public Understanding Sci., 9, 239-260.

Kwok, R., and D. A. Rothrock, 2009: Decline in Arctic sea ice thickness from submarine and ICESat records: 1958-2008. Geophys. Res. Lett., 36, L15501, doi:10.1029/2009GL039035.

Leiserowitz, A., N. Smith, and J. R. Marlon, 2010: Americans knowledge of climate change. Yale Project on Climate Change Communication, $58 \mathrm{pp}$.

Loehle, C., and N. Scafetta, 2011: Climate change attribution using empirical decomposition of historical time series. Open Atmos. Sci. J., 5, 74-86.

Lord, C. G., L. Ross, and M. R. Lepper, 1979: Biased assimilation and attitude polarization: The effects of prior theories on subsequently considered evidence. J. Pers. Soc. Psychol., 37, 2098-2109.

McCright, A. M., 2011: Political orientation moderates Americans beliefs and concern about climate change. Climatic Change, 104, 243-253, doi:10.1007/s10584-010-9946-y.

—_, and R. E. Dunlap, 2011: The politicization of climate change: Political polarization in the American public's views of global warming. Sociol. Q., 52, 155-194.

Mitchell, M. N., 2012: Interpreting and Visualizing Regression Models Using Stata. Stata Press, 558 pp.

Munro, G. D., and P. H. Ditto, 1997: Biased assimilation, attitude polarization, and affect in reactions to stereotype-relevant scientific information. Pers. Soc. Psychol. Bull., 23, 636-653.
, L. K. Lockhart, A. Fagerlin, M. Gready, and E. Peterson, 2002: Biased assimilation of sociopolitical arguments: Evaluating the 1996 U.S. presidential debate. Basic Appl. Soc. Psychol., 24, $15-26$.

National Oceanic and Atmospheric Administration, cited 2011: Arctic report card. [Available online at http://www.arctic. noaa.gov/reportcard/.]

— able online at http://www.esrl.noaa.gov/gmd/ccgg/trends/.]

National Research Council of the National Academies, 2010: $A d$ vancing the Science of Climate Change. NRC, 528 pp.

National Snow and Ice Data Center, cited 2011: Arctic sea ice news and analysis. [Available online at http://nsidc.org/arcticsea icenews/.]

Notz, D., and J. Marotzke, 2012: Observations reveal external driver for Arctic sea-ice retreat. Geophys. Res. Lett., 39, L08502, doi:10.1029/2012GL051094.

Plimer, I., 2009: Heaven and Earth: Global Warming, the Missing Science. Connor Court, 504 pp.

Polar Research Group, cited 2011: The Cryosphere today. University of Illinois at Urbana-Champaign. [Available online at http://arctic.atmos.uiuc.edu/cryosphere/.]

Polar Science Center, cited 2011: Arctic sea ice volume anomaly, version 2. University of Washington. [Available online at http:// psc.apl.washington.edu/wordpress/research/projects/arctic-seaice-volume-anomaly/.]

Polyak, L., and Coauthors, 2010: History of sea ice in the Arctic. Quat. Sci. Rev., 29, 1757-1778.

Read, D., A. Bostrom, M. Granger Morgan, B. Fischhoff, and T. Smuts, 1994: What do people know about global climate change? II. Survey studies of educated laypeople. Risk Anal., 14, 971-982.

Reynolds, T. W., A. Bostrom, D. Read, and M. Granger Morgan, 2011: Now what do people know about global climate change? Survey studies of educated laypeople. Risk Anal., 30, 1520-1538.

Richardson, K., and Coauthors, cited 2009: Synthesis report from climate change: Global risks, challenges and decisions. University of Copenhagen. [Available online at http://www.pikpotsdam.de/news/press-releases/files/synthesis-report-web.pdf.]

Scripps Institution of Oceanography, cited 2012: The early Keeling curve. [Available online at http://scrippsco2.ucsd.edu/program_ history/early_keeling_curve.html.]

Spielhagen, R. F., and Coauthors, 2011: Enhanced modern heat transfer to the arctic by warm atlantic water. Science, $\mathbf{3 3 1}$, 450-453.

Solomon, S., D. Qin, M. Manning, M. Marquis, K. Averyt, M. M. B. Tignor, H. L. Miller Jr., and Z. Chen, Eds., 2007: Climate Change 2007: The Physical Science Basis. Cambridge University Press, 996 pp.

Taber, C. S., and M. Lodge, 2006: Motivated skepticism in the evaluation of political beliefs. Amer. J. Pol. Sci., 50, 755-769.

Van Liere, K. D., and R. E. Dunlap, 1980: The social bases of environmental concern: A review of hypotheses, explanations and empirical evidence. Public Opin. Q., 44, 181-197.

Weart, S. R., 2008: The Discovery of Global Warming: Revised and Expanded Edition. Harvard University Press, 240 pp.

Wood, B. D., and A. Vedlitz, 2007: Issue definition, information processing, and the politics of global warming. Amer. J. Pol. Sci., 51, 552-568.

Zhao, X., 2009: Media use and global warming perceptions: A snapshot of the reinforcing spirals. Commun. Res., 36, 698-723. 